\title{
The role of complementarity of goods in a mixed bundling strategy
}

\author{
Carmen D. Álvarez-Albelo* \\ Departamento de Economía, Contabilidad y Finanzas e Instituto de Investigación Social y Turismo, \\ Universidad de La Laguna, San Cristobal de La Laguna, Spain
}

Received: 25 June 2019

Revised: 28 October 2019

Accepted: 15 November 2019

\begin{abstract}
This paper studies optimal pricing when a monopolist firm produces two complementary goods and may undertake a bundling strategy. To do so, a modified version of Yan and Bandyopadhyay's (2011) framework is used, in which the efficacy of the bundling strategy depends positively on the degree of complementarity, and stand-alone demands of goods may differ in price elasticity. Three main results are obtained. First, mixed bundling turns out to be the optimal strategy. Second, sales and profits from bundled (unbundled) goods increase (decrease) as the products become more complementary, which entails an empirically sensible behavior. Third, the less elastic good and a bundle may be priced equally, when the goods are highly complementary.
\end{abstract}

Keywords: mixed bundling; degree of complementarity of goods; price elasticity; multi-product monopoly

JEL Classification Codes: D21, D42

\section{Introduction}

Selling products in packages, or bundling, is a common strategy of firms when the products they supply are perceived by customers as complementary. Two types of bundling have been identified in the literature, namely, price and product bundling (Stremersch and Tellis, 2002). In the former case, products that compose a package are not integrated and hence bundling per $s e$ does not create value added to consumers. Consequently, the package must be offered at a price discount to make it more attractive to some customers (Estelami, 1999). By contrast, product bundling entails integration of the goods that compose a package as in, for instance, vehicles and telecom systems. The present paper is concerned with price bundling.

Bundling is a usual practice in many economic sectors, such as retailing (Mulhern and Leone, 1991), tourism (Čavlek, 2006) and telecommunications (Srinuan et al., 2014). While these

\footnotetext{
*E-mail: calbelo@ull.edu.es.

Citation: Álvarez-Albelo, C. D. (2020) The role of complementarity of goods in a mixed bundling strategy, Economics and Business Letters, 9(1), 31-40.
}

DOI: 10.17811/ebl.9.1.2020.31-40 
sectors are characterized by some degree of competition, literature has shown that bundling can play a significant role as a monopolist strategy, since it can be used to induce exit and deter entry of potential competitors (Peitz, 2008). Such practices have been carried out in high-tech sectors, as was the case of product bundling by Microsoft (Stremersch and Tellis 2002; Peitz, 2008). In fact, bundling has been studied in the presence of different levels of market competition, including monopolies (Sheikhzadeh and Elahi, 2013; Li et al., 2013) and imperfectly competitive firms (Vamosiu, 2018a, 2018b).

Obviously, the objective of a bundling strategy is none other than to achieve greater profits. Therefore, from a firm's perspective, the decision on whether or not to carry out a bundling policy requires comparing profits from four alternatives, namely, pure stand-alone sales or unbundling, pure bundling, partial mixed bundling and mixed bundling (e.g. Adams and Yellen, 1976; Schmalensee, 1984; Bakos and Brynjolfsson, 1999; Stremersch and Tellis, 2002; Venkatesh and Kamakura, 2003; Li et al., 2013). As stated by Prasad et al. (2010), in the case of a two-product firm, partial mixed bundling consists of selling one product separately and both products as a bundle. By contrast, mixed bundling consists of selling both products separately and also as a bundle.

Noticeably, the degree of complementarity of goods is a crucial issue in the analysis, since it greatly affects a firm's economic results. Quite surprisingly, as stated by Yan and Bandyopadhyay (2011, p. 356), there has been "little research that has considered the optimal pricing of complementary products according to the degree of complementarity." These authors filled this gap in the literature by developing a model involving a monopolist firm that produces two complementary goods. Nonetheless, they only analyzed pure unbundling and pure bundling, and hence were unable to determine the optimal strategy for the firm. Moreover, in their model, the efficacy of the bundling policy is independent of the degree of complementarity of products, which yields a puzzling response of sales and profits to changes in the degree of complementarity. They also left aside the question of how the firm's decisions are affected if the stand-alone demands of goods differ in price elasticity.

The present paper contributes to the literature by analyzing pricing, sales and profits in an extension of Yan and Bandyopadhyay's (2011) framework, in which the efficacy of bundling depends positively on the degree of complementarity of goods, and the stand-alone demands of goods may differ in price elasticity. In order to determine the optimal pricing for the firm, the model is solved for the aforementioned four strategies. A numerical analysis of the response of prices, sales and profits to changes in the degree of complementarity is carried out to check if empirically sensible results are obtained. In addition, different price elastic demands for standalone goods are also considered, which allows getting some insight into the implications of having more versus less elastic goods included in a bundle. ${ }^{1}$

The study of mixed bundling in this setting is pertinent and relevant, since a profit-maximizing firm could hardly renounce serving the demands for stand-alone sales when it undertakes a bundling strategy. In fact, some of the literature has shown that mixed bundling outperforms other strategies in terms of profits (e.g. Adams and Yellen, 1976; Guiltinan, 1987; McAfee et al., 1989; Stremersch and Tellis, 2002). This finding is in line with Guiltinan's (1987, p. 74) observation that "as product lines have broadened in many industries (particularly service industries), the use of mixed price bundling has increased."

The remainder of the paper is organized as follows. Section 2 presents the model. Section 3 analyzes pure unbundling, pure bundling and partial mixed bundling. Section 4 studies mixed bundling. Lastly, Section 5 concludes.

\footnotetext{
${ }^{1}$ The author gratefully recognizes this insight from the reviewer.
} 


\section{The model}

This section describes an extension of Yan and Bandyopadhyay's (2011) model of a monopolist firm that produces complementary goods. The firm produces two goods denoted as $i=1,2$ and faces the demand functions for stand-alone sales (Gupta and Loulou, 1998):

$$
x_{1}=\alpha-\beta p_{1}-\theta \beta p_{2}, \quad x_{2}=\alpha-p_{2}-\theta p_{1}, \quad \alpha>0,0.6 \leq \beta \leq 1,0 \leq \theta<1,
$$

where $x_{i}$ is the demanded quantity of $\operatorname{good} i, p_{i}$ is the price of $\operatorname{good} i, p_{j}$ is the price of the complementary good $j, \alpha$ is the market base and $\theta$ measures the degree of complementarity between the goods, which increases as the value of parameter $\theta$ does. Since $\theta<1$ the goods can never be perfect complements. Unlike Yan and Bandyopadhyay (2011), we assume that the demands in Eq. (1) may exhibit a different sensitivity to the good's price. Indeed, the demand for good 1 can be either less price elastic than the demand for good $2(\beta<1)$ or they can be equally price elastic $(\beta=1)$. The lower bound for $\beta$ ensures a maximum of the profit function in the four strategies.

Moreover, the firm may undertake a bundling strategy that creates a demand segment for bundles. Each bundle is composed of one unit of good 1 and one unit of good 2. The functional form of the demand for bundles takes the form:

$$
x_{B}=\alpha-p_{B}+\theta\left(p_{1}+p_{2}-p_{B}\right), \alpha>0,0 \leq \theta<1,
$$

where $x_{B}$ is the demanded quantity of bundles and $p_{B}$ is the bundle price. There is an expansion of the demand provided that buying the goods separately turns out to be more expensive than purchasing them jointly. In other words, a rise in the price discount associated with a bundle, i.e. $p_{1}+p_{2}-p_{B}$, causes the demand for bundles to increase. The sensitivity of demand to the price discount, which measures the efficacy of the bundling strategy, is captured by $\theta$. Thus, the more complementary the goods are, the more effective the bundling strategy becomes. By contrast, in the demand function considered by Yan and Bandyopadhyay (2011), this sensitivity is independent of the degree of complementarity of goods, which does not seem a reasonable assumption.

In these setting, pricing will be studied when the firm carries out pure unbundling, pure bundling, partial mixed bundling and mixed bundling. The response of prices, sales and profits to changes in $\theta$ will be analyzed through numerical examples using the parameter values in Table 1. Since the stand-alone demands may exhibit different price elasticity, the computation will be performed for $\beta=1$ (both demands are equally price elastic) and $\beta=0.9$ (the demand for good 1 is less price elastic than the demand for good 2). In addition, identical marginal cost in both productions is assumed.

Table 1. Parameter values.

Market base: $\alpha=100$

Price sensitivity: $\beta=\{1,0.9\}$

Degree of complementarity: $0 \leq \theta \leq 0.9$

Marginal cost: $c=20$

\section{Pure unbundling, pure bundling and partial mixed bundling}

\subsection{Pure unbundling}

In a pure unbundling strategy, the firm seeks $p_{i}, i=1,2$, that maximizes the profit function $\pi_{S A}=\left(p_{1}-c\right) x_{1}+\left(p_{2}-c\right) x_{2}$. Solving this problem gives the prices:

$$
p_{1}=\frac{(2-\theta(\beta+1)) \alpha+(2(\beta+\theta)-\theta(\beta+1)(1+\beta \theta)) c}{4 \beta-\theta^{2}(\beta+1)^{2}},
$$




$$
p_{2}=\frac{(2 \beta-\theta(\beta+1)) \alpha+(2 \beta(1+\beta \theta)-\theta(\beta+1)(\beta+\theta)) c}{4 \beta-\theta^{2}(\beta+1)^{2}} .
$$

A look at Eqs. (3) and (4) reveals that $p_{1}=p_{2}$ and hence $x_{1}=x_{2}$ provided that $\beta=1$. By contrast, when $\beta<1$, the firm charges a higher (lower) price to the less (more) elastic good, i.e. $p_{1}>p_{2}$. Thus, the standard result in the literature referring to a multi-product monopoly that produces complementary goods is obtained. Indeed, as the degree of complementarity increases, profits can be augmented by setting a lower price for the more elastic good in order to expand the demand for the less elastic product. Thus, the firm might even find it optimal to price the more elastic good below the marginal cost (Tirole, 1990).

Figure 1. Equilibrium response to changes in $\theta$ and $\beta$ under pure unbundling.
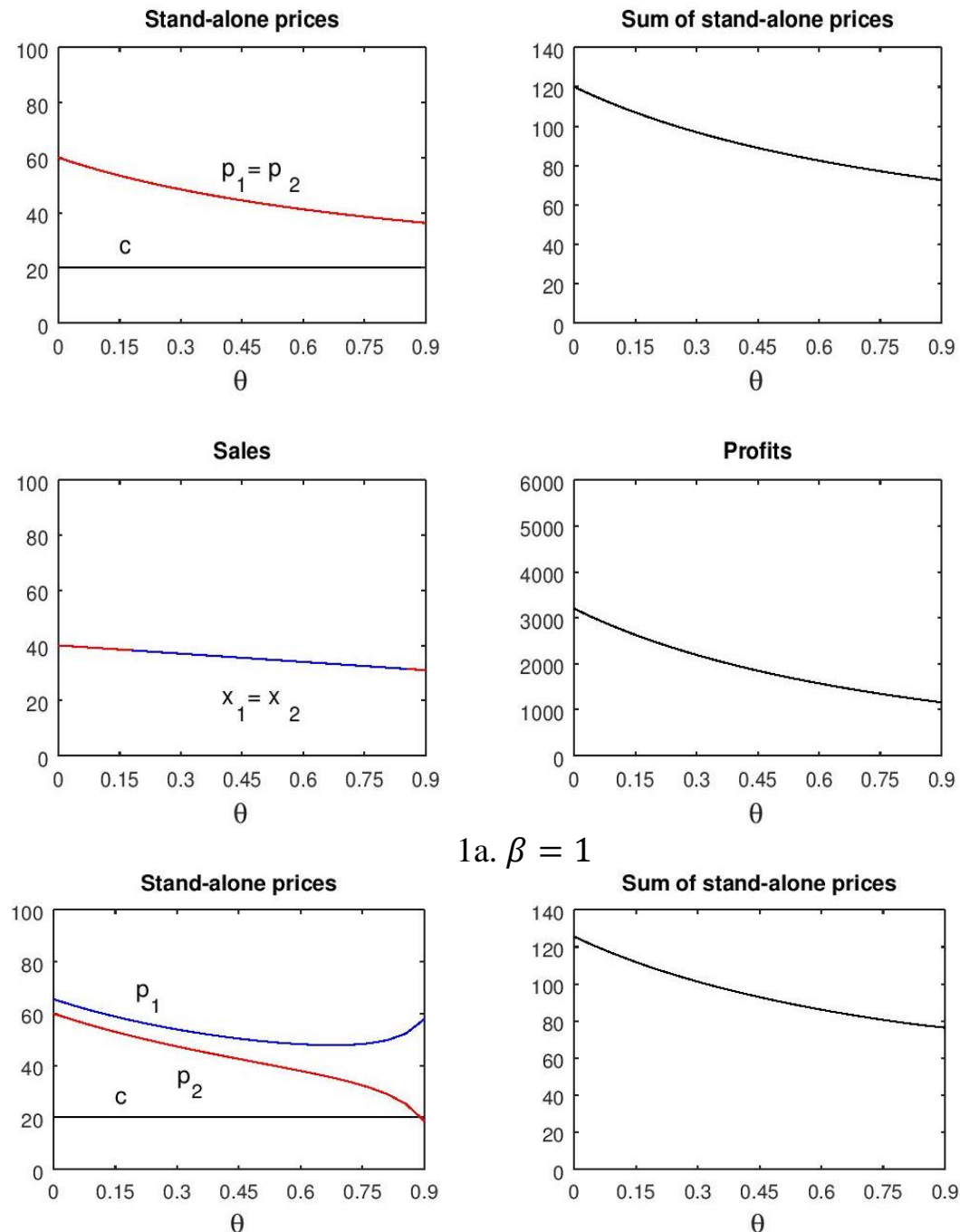

1a. $\beta=1$
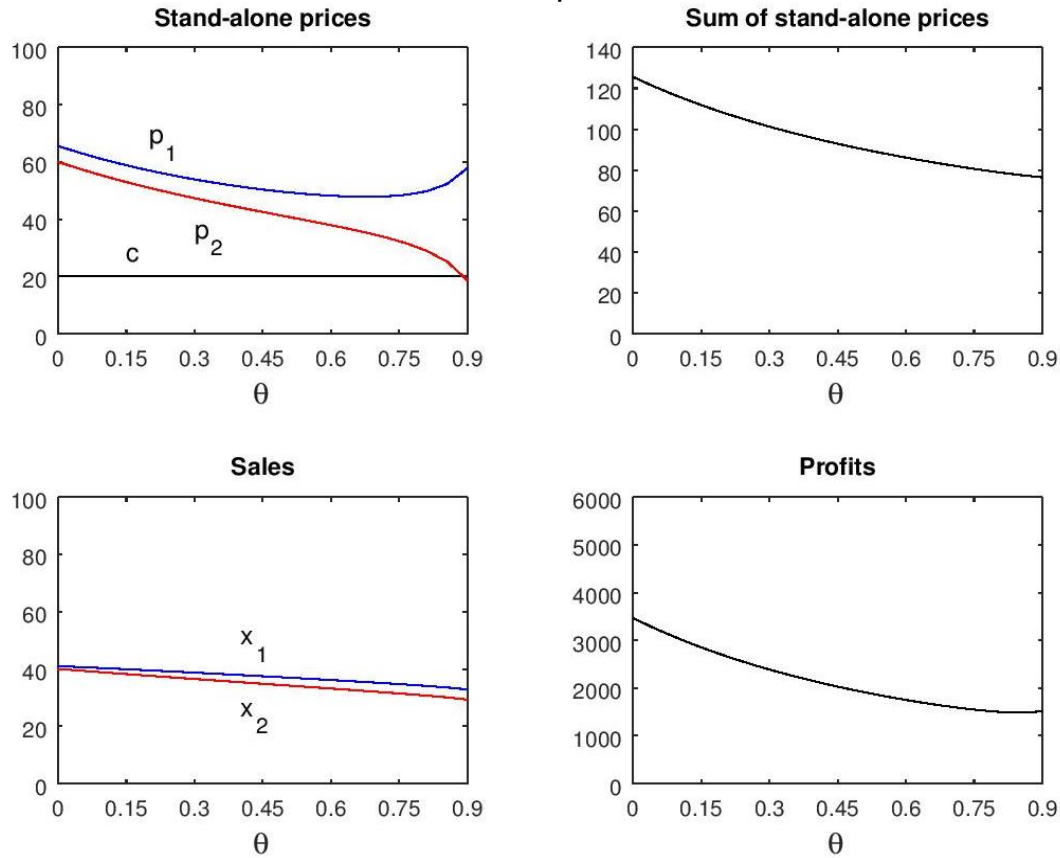

1b. $\beta=0.9$ 
Figure 1 depicts the response of variables to increases in the degree of complementarity under $\beta=1$ (panel 1a) and $\beta=0.9$ (panel $1 \mathrm{~b}$ ), using the parameter values in Table 1 . The figure shows the aforementioned behavior of prices and sales when good 1 becomes less elastic than good 2. It is worth noting that the existence of a less elastic good augments the sum of standalone prices. This result will affect the behavior of variables in a pure bundling strategy.

\subsection{Pure bundling}

The firm only serves the demand in Eq. (2) when a pure bundling strategy is undertaken. Therefore, the maximization of profits, $\pi_{P B}=\left(p_{B}-2 c\right) x_{B}$, consists of choosing $p_{B}$, taken the sum of stand-alone prices in Eqs. (3) and (4) as given, which yields:

Figure 2. Equilibrium response to changes in $\theta$ and $\beta$ under pure bundling.
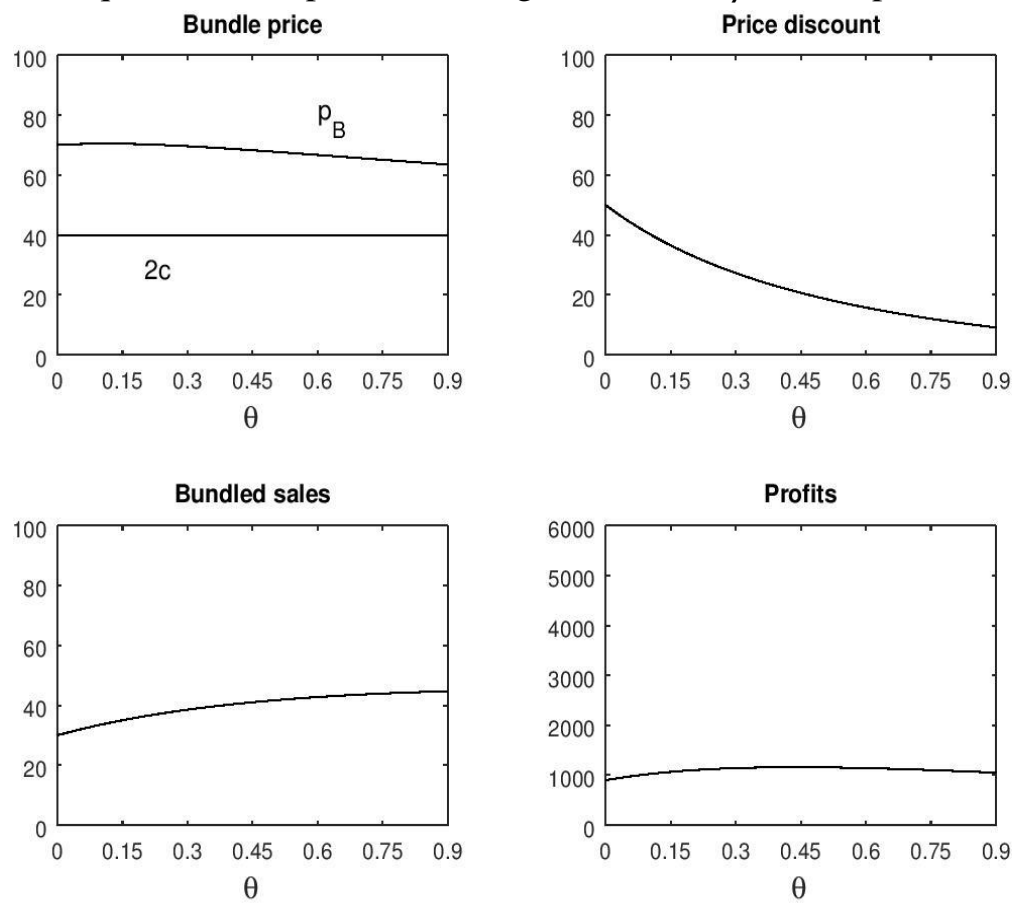

2a. $\beta=1$
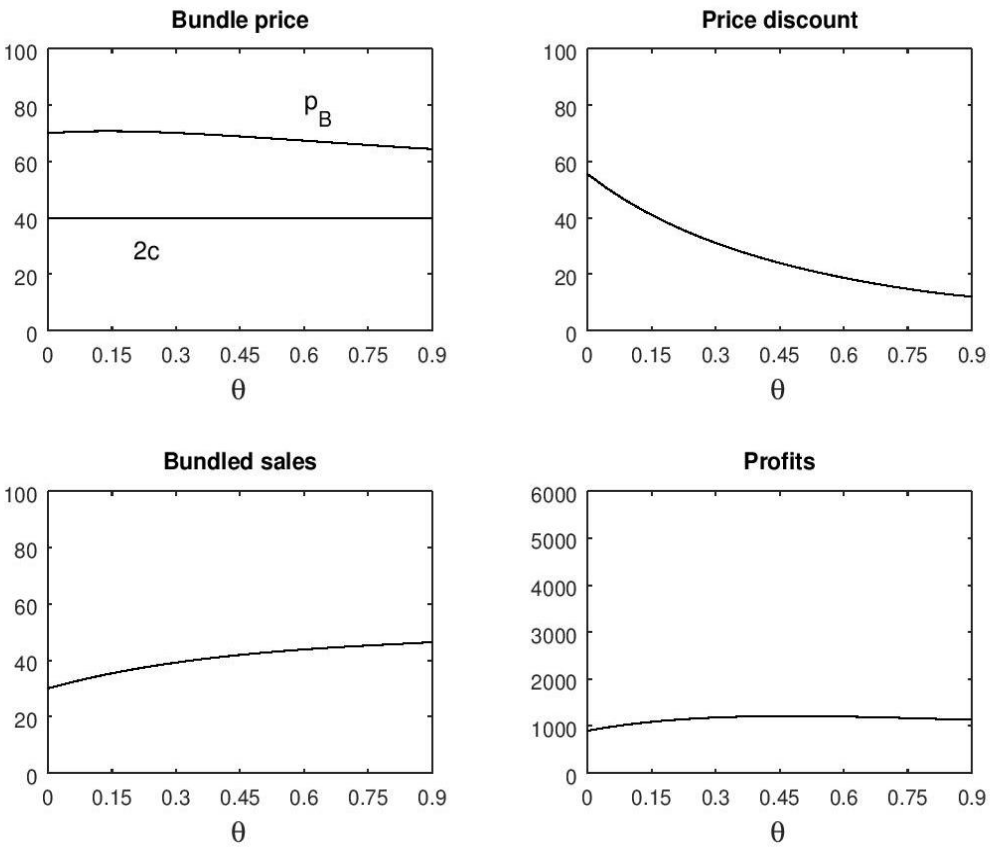

2b. $\beta=0.9$ 


$$
p_{B}=\frac{\alpha+(1+\theta) 2 c+\theta\left(p_{1}+p_{2}\right)}{2(1+\theta)} .
$$

Eq. (5) shows a direct relation between the sum of stand-alone prices and the bundle price.

Figure 2 depicts the results from the numerical exercises which, for this parameter configuration, show few changes when switching from panel $2 \mathrm{a}$ to panel $2 \mathrm{~b}$. As commented previously, the sum of stand-alone prices becomes higher when $\beta=0.9$ than with $\beta=1$ and, consequently, so do the bundle price and the price discount.

Figure 3. Equilibrium response to changes in $\theta$ and $\beta$ under partial mixed bundling.
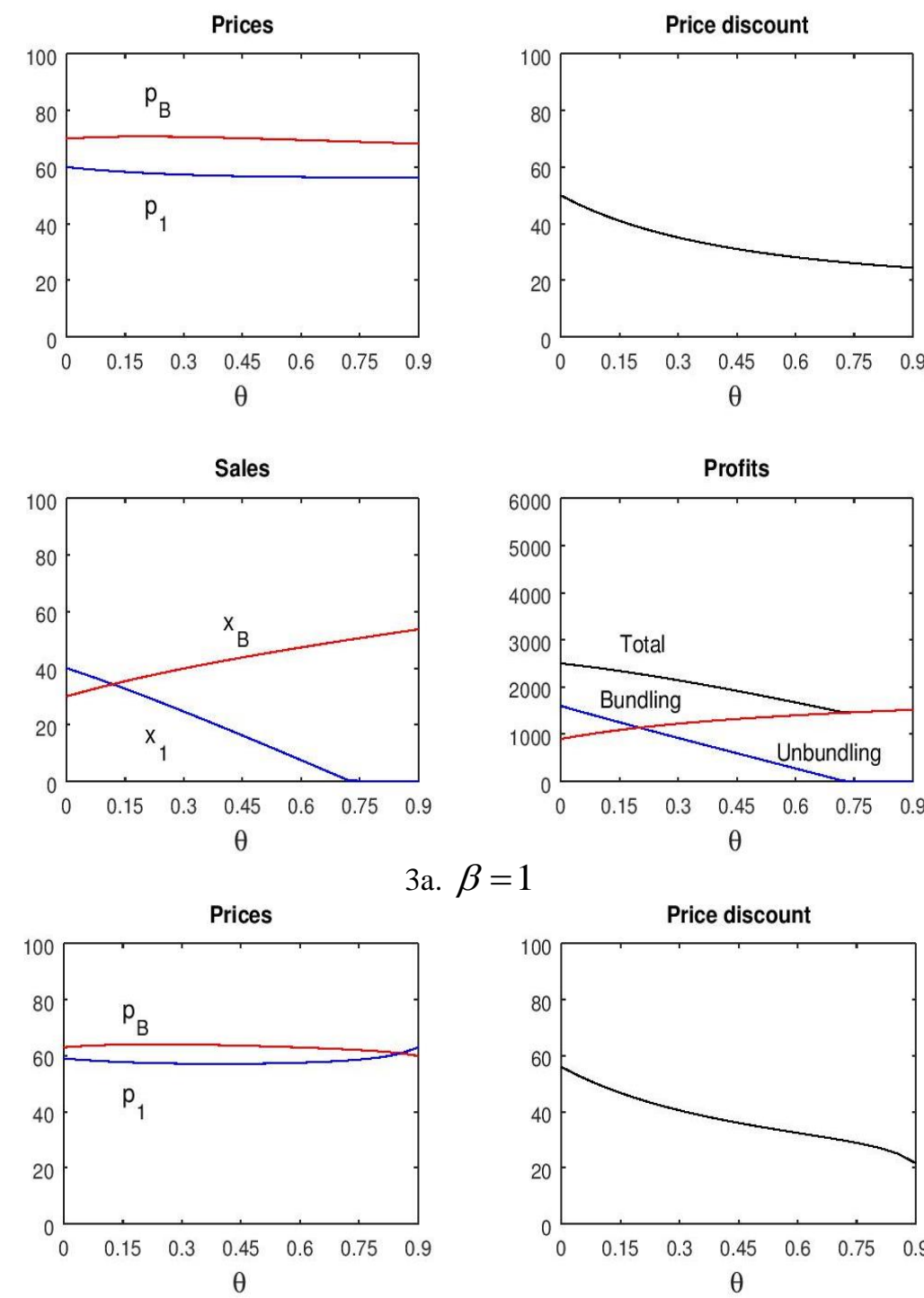

3a. $\beta=1$
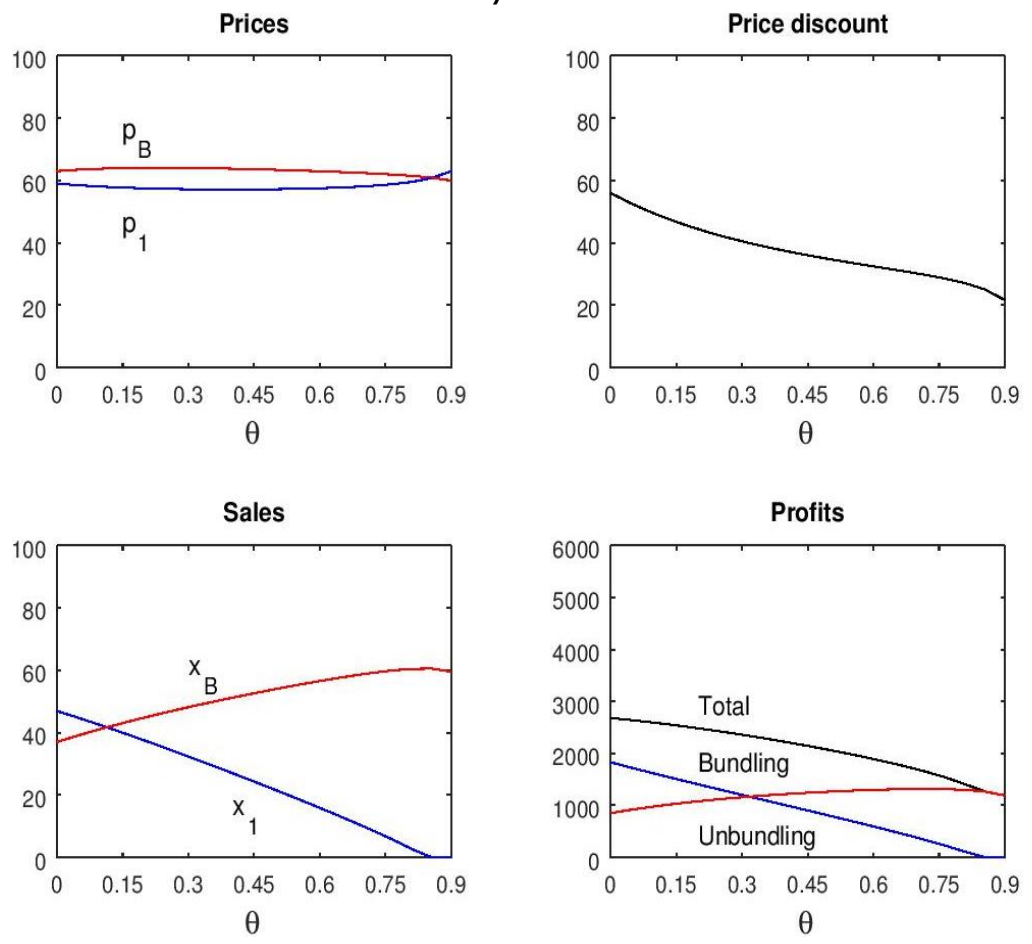

3b. $\beta=0.9$ 


\subsection{Partial mixed bundling}

The firm might want to offer good 2 only within a bundle since, as shown in panel $1 \mathrm{~b}$, its contribution to profits declines as $\theta$ rises. Obviously, this reasoning does not apply if $\beta=1$. Thus, the firm would undertake a partial mixed bundling strategy, in which only good 1 and bundles are offered. The firm takes the price in Eq. (4) as given and maximizes the profit function $\pi_{P M B}=\left(p_{1}-c\right) x_{1}+\left(p_{B}-2 c\right) x_{B}$, which includes profits from selling good 1 (unbundling) and packages (bundling). The equilibrium prices are equal to:

$$
\begin{gathered}
p_{1}=\frac{(2+3 \theta) \alpha+2(1+\theta)(\beta-\theta) c-\theta(2 \beta(1+\theta)-\theta) p_{2}}{4 \beta(1+\theta)-\theta^{2}}, \\
p_{2}=\frac{(2 \beta+\theta) \alpha+\left(4 \beta+5 \beta \theta-2 \theta^{2}\right) c+\beta \theta(2-\theta) p_{2}}{4 \beta(1+\theta)-\theta^{2}} .
\end{gathered}
$$

Looking at Eqs. (6) and (7), it follows that a reduction in $p_{2}$ (in Figure 1) causes an increase in $p_{1}$ and a decrease in $p_{B}$.

The results from the numerical exercises are depicted in Figure 3. The decline in $p_{2}$ as the goods become more complementary (in Figure 1) expands the demand of good 1 and hence its price. As a result, for high values of $\theta$ the quantity of good 1 hits a corner and hence only bundles are sold. Moreover, when $\beta=0.9$ the firm has incentives to further increase $p_{1}$, which becomes even higher than $p_{B}$ when the goods are nearly perfect complements. The results in both panels show an increase (decrease) in sales and profits from bundling (unbundling), as the goods become more complementary, which makes sense from an empirical point of view. This result is due to the assumption that the efficacy of the bundling policy depends positively on parameter $\theta$.

\section{Mixed bundling}

The firm seeks the stand-alone prices $p_{i}, i=1,2$, and the bundle price $p_{B}$ that maximize its profit function, $\pi_{M B}=\left(p_{1}-c\right) x_{1}+\left(p_{2}-c\right) x_{2}+\left(p_{B}-2 c\right) x_{B}$, which includes profits from stand-alone sales of each good (unbundling) and bundled sales (bundling). The first order conditions (FOCs) of the firm's maximization problem are:

$$
\begin{gathered}
\frac{\partial \pi_{M B}}{\partial p_{1}}=\alpha+(\beta+\theta-2 \theta) c-2 \beta p_{1}-\theta(\beta+1) p_{2}+\theta p_{B}=0 \\
\frac{\partial \pi_{M B}}{\partial p_{2}}=\alpha+(1+\beta \theta-2 \theta) c-\theta(\beta+1) p_{1}-2 p_{2}+\theta p_{B}=0 \\
\frac{\partial \pi_{M B}}{\partial p_{B}}=\alpha+2(1+\theta) c+\theta\left(p_{1}+p_{2}\right)-2(1+\theta) p_{B}=0
\end{gathered}
$$

Regarding the second order conditions (SOCs), the profit function presents a local maximum as shown in Appendix A. As expected, the FOCs show that stand-alone goods and bundles are strategic complements, since they present a direct relation. The equilibrium prices come from solving the system of equations composed of Eqs. (8), (9) and (10).

Eqs. (8) and (9) show that for $\beta=1$ it holds that $p_{1}=p_{2}$ and hence $x_{1}=x_{2}$. By contrast, the condition $\beta<1$ yields $p_{1}>p_{2}$.

The numerical examples in Figure 4 illustrate the results. A comparison of total profits shown in the figures reveals that mixed bundling is the optimal strategy for the firm. Like under pure unbundling and partial mixed bundling, having a less elastic good creates incentives for reducing $p_{2}$ in order to expand the stand-alone demand of good 1 . This expansion, in turn, raises $p_{1}$. Even good 1 can be priced as a bundle when the products are highly complementary. Moreover, under the assumption that the efficacy of the bundling policy depends positively on $\theta$, the behavior of stand-alone and bundled sales turns out to be empirically sensible. Indeed, an increase in $\theta$ reduces the stand-alone demands, thus causing a decline in stand-alone sales. By contrast, the bundling policy becomes more effective as $\theta$ rises, which increases bundled 
sales as the products become more complementary. The model also delivers sound results regarding the response of profits to changes in the degree of complementarity. Indeed, an increase (decrease) in profits from bundled (unbundled) sales would be expected when consumers perceive the goods as more complementary.

Figure 4. Equilibrium response to changes in $\theta$ and $\beta$ under mixed bundling.

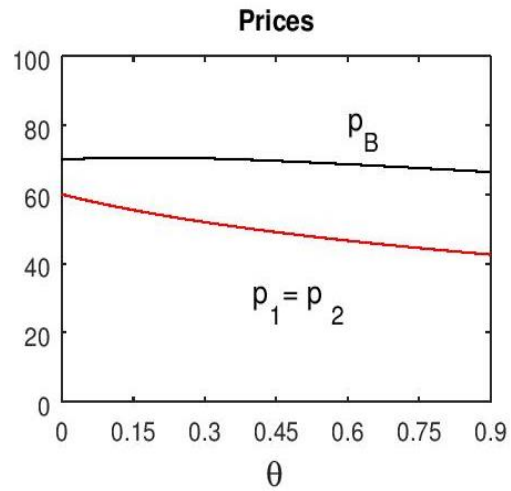

Price discount
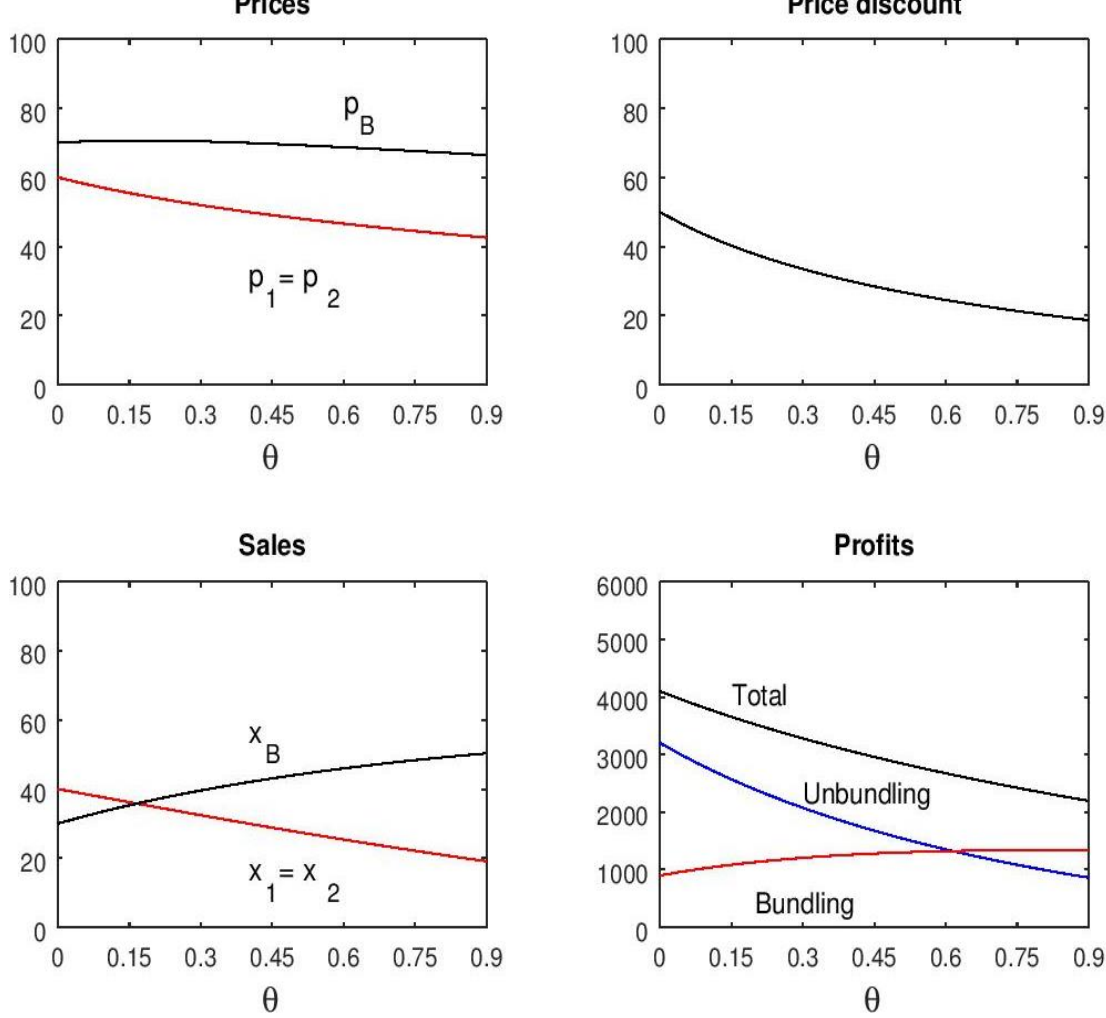

4a. $\beta=1$
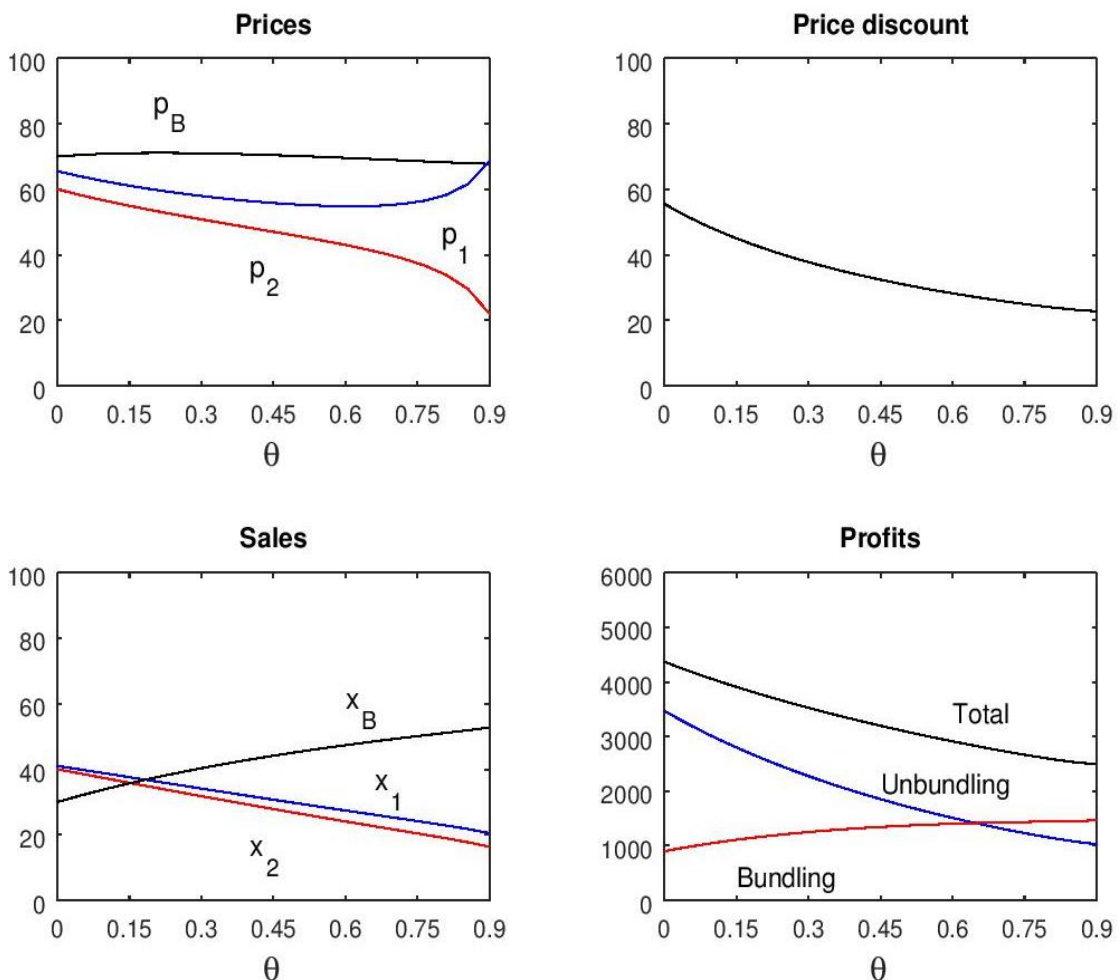

4b. $\beta=0.9$ 


\section{Conclusion}

Yan and Bandyopadhyay (2011) filled a gap in the literature by studying pricing and profits under pure unbundling and pure bundling according to the degree of complementarity of goods. To do this, they developed a simple model that stands for a monopolist firm that produces two complementary goods. Nonetheless, these authors left aside the analysis of mixed bundling which, according to some of the literature, is the optimal strategy for a firm. Moreover, mixed bundling in their model delivers puzzling results regarding the response of sales and profits when the degree of complementarity of goods is increased.

This paper has extended Yan and Bandyopadhyay's (2011) model to allow for the efficacy of bundling to depend positively on the degree of complementarity of goods. In addition, differences in price elasticity of stand-alone demands of goods have also been considered. Three main results have been obtained. First, mixed bundling is the optimal strategy, which is in line with the observed development of this strategy in many economic sectors. Second, the model delivers a sensible response of sales and profits to changes in the degree of complementarity of goods. More specifically, bundled (stand-alone) sales and profits from selling bundles (standalone goods) increase (decrease) as the goods become more complementary. Third, it could be optimal to price equally the less elastic good and a bundle when the goods are highly complementary.

Therefore, this paper has provided a suitable framework for studying mixed bundling, when complementary goods are being supplied. The model can be extended in several directions, such as incomplete information (e.g. Palfrey, 1983) and advertising (e.g. Yan et al., 2014). In addition, since most markets operate under some degree of competition, the absence of interfirm competition (e.g. Vamosiu, 2018a, 2018b) is clearly a limitation of the analysis carried out here. These issues constitute promising areas for future research.

\section{References}

Adams, W. J., and Yellen, J. L. (1976) Commodity bundling and the burden of monopoly, Quarterly Journal of Economics, 90(3), 475-498.

Bakos, Y., and Brynjolfsson, E. (1999) Bundling information goods: Pricing, profits, and efficiency, Management Science, 45(12), 1613-1630.

Čavlek, N. (2006) Travel and tourism intermediaries. In Dwyer, L. and Forsyth, P. (Eds.): International Handbook on the Economics of Tourism, Edward Elgar: Cheltenham, 155-172.

Estelami, H. (1999) Consumer savings in complementary product bundles, Journal of Marketing Theory and Practice, 7(3), 107-114.

Guiltinan, J. P. (1987) The price bundling of services: A normative framework, Journal of Marketing, 51(2), 74-85.

Gupta, S., and Loulou, R. (1998) Process innovation, product differentiation, and channel structure: Strategic incentives in a duopoly, Marketing Science, 17(4), 301-316.

Li, M., Feng, H., Chen, F., and Kou, J. (2013) Numerical investigation on mixed bundling and pricing of information products, International Journal of Production Economics, 144(2), 560-571.

McAfee, R. P., McMillan J., and Whinston, M. D. (1989) Multiproduct monopoly, commodity bundling, and correlation of values, Quarterly Journal of Economics, 104(2), 371-383.

Mulhern, F. J., and Leone, R. P. (1991) Implicit price bundling of retail products: A multiproduct approach to maximizing store profitability, Journal of Marketing, 55(4), 6376.

Palfrey, T. R. (1983) Bundling decisions by a multiproduct monopolist with incomplete information, Econometrica, 51(2), 463-483. 
Peitz, M. (2008) Bundling may blockade entry, International Journal of Industrial Organization, 26(1), 41-58.

Prasad, A., Venkatesh, R., and Mahajan, V. (2010) Optimal bundling of technological products with network externality, Management Science, 56(12), 2224-2236.

Schmalensee, R. (1984) Gaussian demand and commodity bundling, Journal of Business, 57(1), S211-S230.

Sheikhzadeh, M., and Elahi, E. (2013) Product bundling: Impacts of product heterogeneity and risk considerations, International Journal of Production Economics, 144(1), 209-222.

Srinuan, P., Srinuan, C., and Bohlin, E. (2014) An empirical analysis of multiple services and choices of consumer in the Swedish telecommunications market, Telecommunications Policy, 38(5-6), 449-459.

Stremersch, S., and Tellis, G. J. (2002) Strategic bundling of products and prices: A new synthesis for marketing, Journal of Marketing, 66(1), 55-72.

Tirole, J. (1990) La teoría de la organización industrial, Barcelona: Editorial Ariel.

Vamosiu, A. (2018a) Optimal bundling under imperfect competition, International Journal of Production Economics, 195, 45-53.

Vamosiu, A. (2018b) Compatibility and bundling of stand and No stand-alone use complements, International Journal of Production Economics, 201, 62-74.

Venkatesh, R., and Kamakura, W. (2003) Optimal bundling and pricing under a monopoly: Contrasting complements and substitutes from independently valued products, The Journal of Business, 76(2), 211-231.

Yan, R., and Bandyopadhyay, S. (2011) The profit benefits of bundle pricing of complementary products, Journal of Retailing and Consumer Services, 18(4), 355-361.

Yan, R., Myers, C., Wang, J., and Ghose, S. (2014) Bundling products to success: The influence of complementarity and advertising, Journal of Retailing and Consumer Services, 21(1), 4853.

\section{Appendix A}

The Hessian matrix associated to the system of equations is:

$$
H\left(p_{1}, p_{2}, p_{B}\right)=\left(\begin{array}{ccc}
-2 \beta & -\theta(\beta+1) & \theta \\
-\theta(\beta+1) & -2 & \theta \\
\theta & \theta & -2(1+\theta)
\end{array}\right) .
$$

Since the determinants of the Hessian matrix are:

$$
\begin{gathered}
\left|H\left(p_{1}\right)\right|=-2 \beta<0, \\
\left|H\left(p_{1}, p_{2}\right)\right|=4 \beta-\theta^{2}(\beta+1)^{2}>0, \\
\left|H\left(p_{1}, p_{2}, p_{B}\right)\right|=-2\left((1+\theta)\left(4 \beta-\theta^{2}(\beta+1)^{2}\right)-\theta^{2}(1-\theta)(\beta+1)\right)<0,
\end{gathered}
$$

the SOCs show that the profit function presents a local maximum. 